\title{
Output-Only Damage Detection of Steel Beam Using Moving Average Filter
}

\author{
Hadi Kordestani, Yi-Qiang Xiang $(\mathbb{D}$, and Xiao-Wei Ye $\mathbb{D}$ \\ Zhejiang University, Hangzhou, China \\ Correspondence should be addressed to Yi-Qiang Xiang; xiangyiq@zju.edu.cn
}

Received 5 October 2017; Accepted 28 December 2017; Published 28 January 2018

Academic Editor: Emanuele Reccia

Copyright (C) 2018 Hadi Kordestani et al. This is an open access article distributed under the Creative Commons Attribution License, which permits unrestricted use, distribution, and reproduction in any medium, provided the original work is properly cited.

\begin{abstract}
This paper provides a simple and direct output-only baseline-free method to detect damage from the noisy acceleration data by using Moving Average Filter (MAF). MAF is a convolution approach based on a simple filter kernel (rectangular shape) that works as an averaging method to smooth signal and remove incorporated noise. In this paper, a method is proposed to employ MAF to smooth acceleration signals obtained from a series of accelerometers and determine the damage location along a steel beam. To verify the proposed method, a simply supported beam was modelled through a 3D numerical simulation and an experimental model under a moving vehicle load. The response acceleration data was then recorded at a sampling frequency of $500 \mathrm{~Hz}$. Finally, damage location was identified by applying the proposed method. The results showed that the proposed method can accurately estimate the damage location from the acceleration signal without applying any frequency filtering or baseline correction.
\end{abstract}

\section{Introduction}

Infrastructures, such as bridges, play an important role in city life and are exposed to various kinds of excitation during their operational life. Structural Health Monitoring (SHM) is a tool to control safety and detect possible damage from structural responses. In some cases, it is impossible to measure the operational load exerted on a bridge, for example, under heavy traffic [1]. In such cases, where a complete knowledge of excitation is not available, output-only modal identification and damage detection methods can be used.

Obtaining a structural vibration response by an accelerometer is one of the easiest and cheapest approaches to SHM. Accelerometers are easy to install at virtually every point along the structure and can provide time-history acceleration data at a wide range of sampling frequencies. Using accelerometers in damage detection methods reduces the cost of SHM significantly.

Acceleration data contain responses of all frequencies and show singularities when damage occurs. Such singularities in acceleration signals cannot be observed by the naked eye. Several researchers dealt with the acceleration data to find these singularities using different methods, such as waveletbased methods [2-5], Random Decrement Technique (RDT) $[1,6-9]$, and Blind Source Separation (BSS) methods [10-14].

Hester and González [2], Balafas and Kiremidjian [3], and Cantero and Basu [4] worked on wavelet transform analysis to find damage and singularities from acceleration signals. The wavelet transform output-only method exhibits large potentials for detecting singularities and damage to structures and bridges and can easily identify the damage with a delta value of 0.1 (where delta refers to the ratio of the crack height to the member height) in a noise-free dataset. Hester and González [5] showed that the impact of the road profile can generate a significant error, affecting structural damage results identified by the wavelet-based methods.

Introduced by Cole in 1968, RDT is one of the most promising output-only techniques when the controlled or initial excitation cannot be measured. RDT is a special averaging method to obtain the free response from output-only data [15]. Further, Ibrahim et al. [1] illustrated the application of RDT for multisignal processing to find modal parameters. Later on, Vandiver et al. [6] offered a mathematical solution for RDT, wherein the input force was considered as a zeromean stationary Gaussian random noise. The most important 
problem with the application of RDT in SHM is the fact that operation loads such as those developed by wind, traffic, and earthquakes are nonstationary in nature. Several researchers tried to either improve or combine RDT with other methods such as neural network technique [7] and empirical mode decomposition [8] to find damage from nonstationary excitation loads. Buff et al. [9] presented a systematic procedure to implement the RDT for modal identifications and damage detection on an arbitrary system.

As mentioned above, ambient vibration usually comes from nonstationary or the multisource excitations. Blind Source Separation algorithms comprise another category of output-only methods, where the signal is decomposed to its components. Two famous techniques for BSS are the Independent Component Analysis (ICA) and the SecondOrder Blind Identification (SOBI) [10, 12]. Kerschen et al. [11] found a one-to-one relationship between vibration modes and ICA modes for low damped systems. They well illustrated that the vibration mode is represented by the columns of the mixing matrix. So, natural frequencies and damping ratios can be calculated through SDOF techniques for mixing matrix columns. Huang and Nagarajaiah [13] combined a BSS technique, namely, SOBI, with wavelet to find damage across a bridge. They proved that their improved SOBI can find more modal parameters with limited sensors. Loh et al. [14] compared the results of damage detection using BSS-SOBI for the bridge with other damage detection methods.

All of the above methods need to determine modal parameters for damage detection. Yan and Golinval [16] used Kalman model to detect damage from output-only data. The Kalman model does not need the modal identification, which is an advantage over the methods above. They built the Kalman model using stochastic subspace identification and computed residual error as a damage index $[17,18]$.

Averaging methods tend to smooth a signal, making it seemingly easier to understand. Such smoothed signals can then be used as a modal parameter identifier or a damage indicator. Moving Average Filter (MAF) is one of the most popularly used methods for real-time processing in the industry, because of its simplicity and noise attenuation capability [19]. However, it is not a good filter in the frequency domain because it cannot separate a band of frequencies from another band [20]. González and Hester [21] applied MAF twice to find damage location using acceleration data obtained from a numerical model.

The aim of present paper is to propose a method that can work with noisy acceleration data and can locate damage with no need of using the baseline or FEM model. The proposed approach uses a series of accelerometers to find the damage in laboratory. Accordingly, as a first step, MAF makes the signals smooth, and next, the damage and its location are highlighted along the smoothed signals. Then, reapplication of MAF ends up predicting the baseline. In the next step, a damage index is defined as the sum of squares of the acceleration data, so as to transform the plot from time-history domain to scalar values (column type plot). These scalar values show the damage location near the accelerometer, where the index is maximal. A 3D numerical model of a simply supported beam under moving load (vehicle simulation)

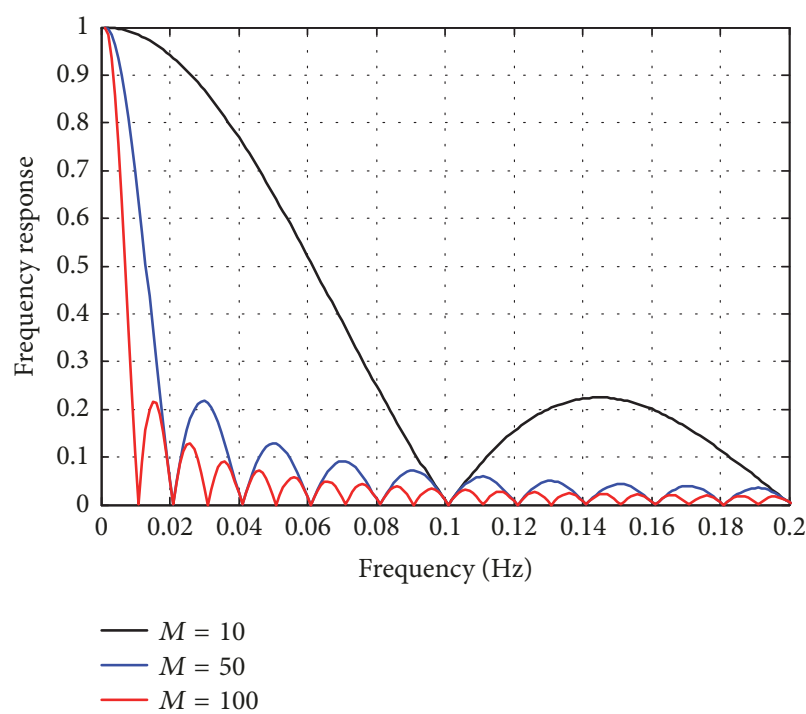

FIgURE 1: Frequency response of MAF using different spans $M$.

is then developed and analyzed to obtain acceleration data at sampling frequency of $500 \mathrm{~Hz}$. Additionally, several damage scenarios are considered at different locations and a sensitivity analysis is performed to study the effect of changes in the moving load velocity. According to the numerical model, an experimental work is then conducted to prove the accuracy of the proposed method.

\section{Basic Theory and Method}

MAF is one of the fastest filtering methods in digital signal processing. A significant advantage of MAF is its random noise reduction capability while keeping the signal sharp. This makes MAF the best filter for time domain signals [20]. As shown in (1), MAF will replace each acceleration point $a(t)$ at instant $t$ with average of the points in the vicinity of $t$

$$
\bar{a}(t)=\frac{1}{M} \sum_{j=-(M-1) / 2}^{j=(M-1) / 2} a(t+j \Delta t),
$$

where $M$ is MAF's span and $\Delta t$ is the time step. For example, if $M$ equals 125, the 100th sample of the smoothed signal is average signal value from the 38 th point to the 162 nd point.

It should be noticed that MAF is a convolution of the input signal with a rectangular pulse $(\ldots, 0,0,0,1 / M$, $1 / M, 1 / M, M$ times, $0,0,0, \ldots)[20]$. Noise attenuation capability of MAF is evaluated based on square-root of MAF span (e.g., if $M=100$, MAF attenuates the noise by a factor of 10). Applying Fourier transform on the rectangular pulse, (1) can be rewritten in the frequency domain as follows [20]:

$$
H[f]=\frac{\sin (\pi f M)}{M \sin (\pi f)},
$$

where $f$ is the frequency, $M$ is MAF's span, and $H[f]$ is the frequency response. Equation (2) is plotted in Figure 1 by using 3 spans of $M=10,50$, and 100 . The figure shows that 


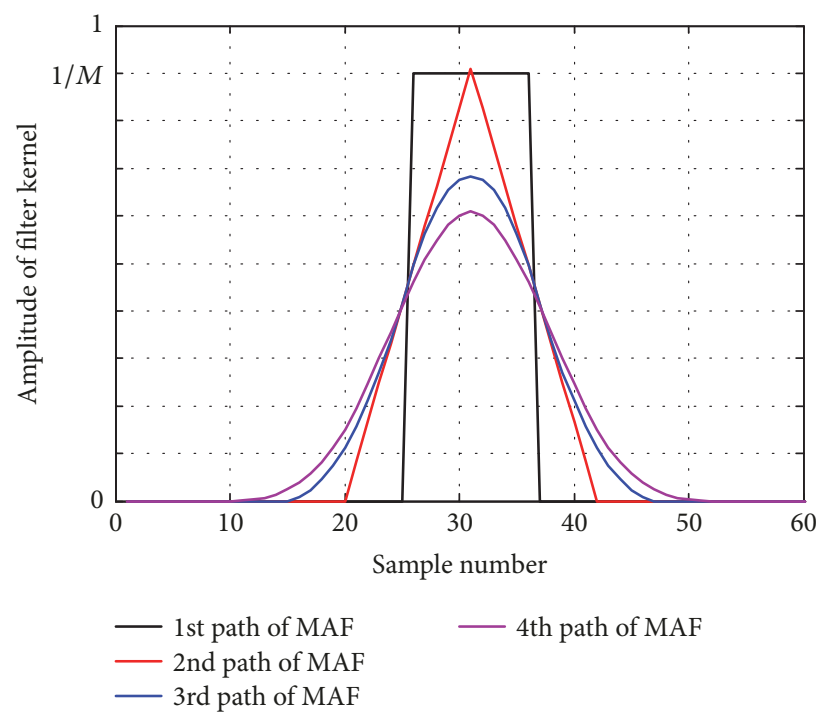

(a) Filter kernels of multipass MAF

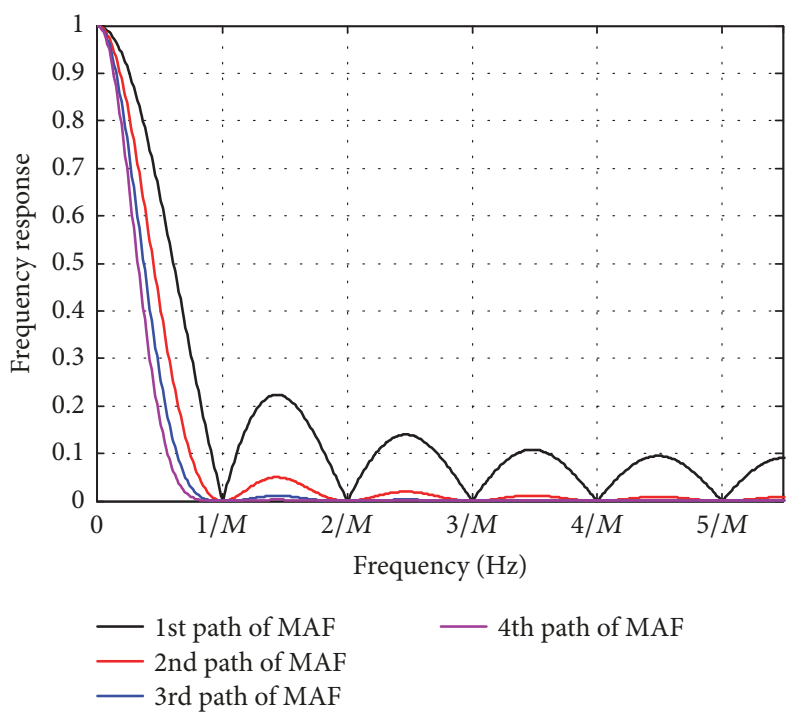

(b) Frequency response of multipass MAF

FIGURE 2: Filter kernels of MAF when applied more than once and its frequency response using FFT.

MAF works as a low-pass filtering method with poor stopband attenuation.

Theoretically, it is possible to use MAF more than once. The kernel of MAF is a rectangular pulse, so that using MAF twice is equivalent to using a triangular filter kernel (rectangular filter kernel convolved to itself); similarly, using MAF 4 times means having a filter kernel of Gaussian shape [20]. Figure 2 shows the effect of using MAF more than once in terms of filter kernel and frequency response. From Figure 2, it is clear that using MAF several times improves the stop-band behavior.

So far, the filtering method to smooth the signal and attenuate random noise was described. Now, a numerical model is required to show the effect of MAF on acceleration signals. For such a purpose, a simply supported beam under a moving load was modelled by finite-element method. The response of the beam under the excitation load $f(t)$ was solved using the second-order matrix differential equation, given as follows:

$$
N \ddot{y}(t)+C \dot{y}(t)+K y(t)=f(t),
$$

where $N, C$, and $K$ are mass, damping, and stiffness matrixes, respectively. The variables $\ddot{y}(t), \dot{y}(t)$, and $y(t)$ are vertical acceleration, vertical velocity, and vertical displacement, respectively. A compressive load moving at some constant velocity along vertical direction was assumed as loading function $f(t)$.

Typically, bridges are the low damped systems [2, 21]. As such, the present study ignored the damping term in (3). A crack of $0.003 \mathrm{~m}$ width and different depths was considered as the damage to the structure.

In order to identify the damage position, a step-by-step procedure was adopted in the present research. First of all, the acceleration time history was obtained from different points located at the bottom of the bridge deck. These data can be obtained from either laboratory experiments or finiteelement models. Then, the best MAF span was determined by numerical modelling. Next, MAF was applied to each set of data to smooth signals and provide a baseline. Finally, a damage index was defined to estimate the location of nearest damage on either laboratory or numerical models. The described procedure is schematically shown in Figure 3.

\section{Laboratory and Numerical Models of the Simply Supported Beam}

3.1. Laboratory Model. In order to utilize the proposed method and examine its accuracy, a laboratory model was constructed. The model was comprised of five simply supported steel beams with $6 \mathrm{~m}$ length and an $I$-shape section profile with overall dimensions of $0.072 \mathrm{~m} \times 0.005 \mathrm{~m}$ (flanges) and $0.112 \mathrm{~m} \times 0.005 \mathrm{~m}$ (web) (the flanges of beam were used as a lane for a truck in the laboratory and a moving load in the numerical model). The density, Young's modulus, and Poisson's ratio of the steel material were $7850 \mathrm{~kg} / \mathrm{m}^{3}, 200 \mathrm{GPa}$, and 0.3 , respectively. In the laboratory model, a vehicle served as a real moving load. In the numerical model, however, the moving load was applied to the beam in terms of a pressure on the lanes with an area of $0.15 \mathrm{~m} \times 0.01 \mathrm{~m}$. When the moving load passed the steel beam at different speeds, the acceleration data were recorded by accelerometers installed at 9 stations along the steel beam with a fixed distance of $0.6 \mathrm{~m}$. Figure 4 shows the positions of accelerometers installed on the experimental model. Figure 5 shows the beams, vehicle, and few of the accelerometers. Figure 6 shows the width and depth of a typical damage crack simulated in these beams in the experimental study.

The accelerometers attached to the bottom of the beam and the flanges of the beam served as a lane for the vehicle, so that the vehicle could easily travel along the beam in a 


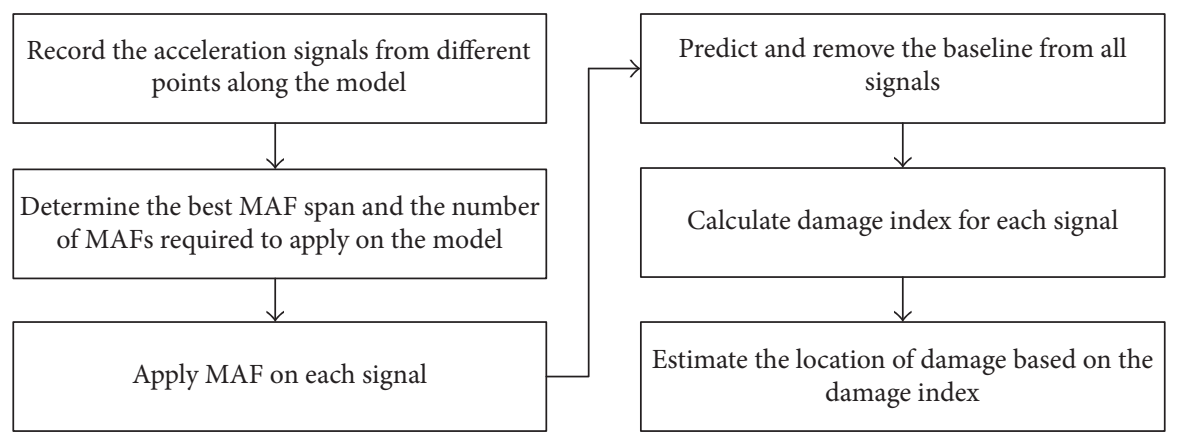

FIGURE 3: General flowchart of damage detection based on MAF.

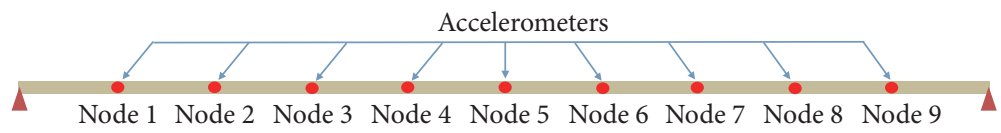

FIGURE 4: Locations of accelerometers to record acceleration data.

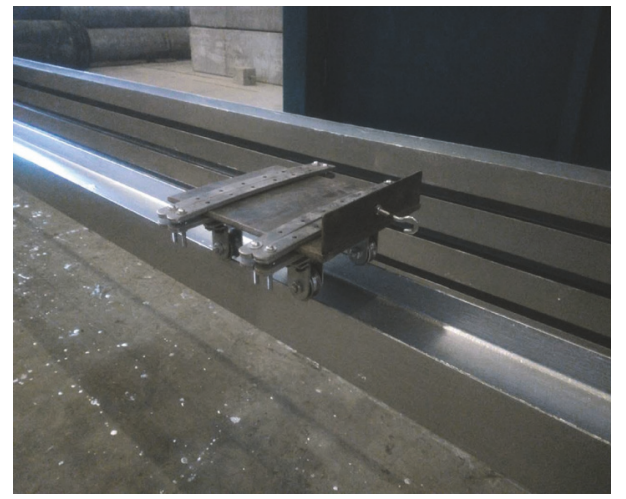

(a)

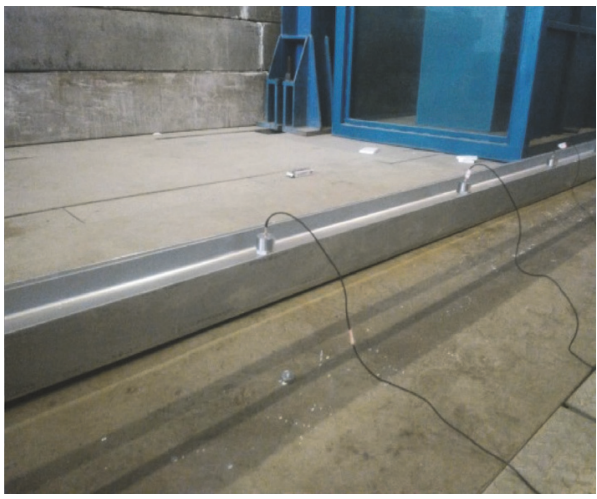

(b)

FIGURE 5: A general view of the vehicle (a) and accelerometers (b).

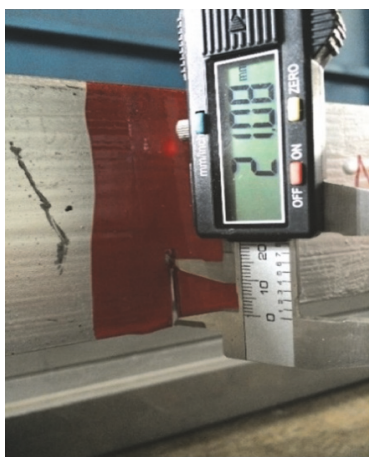

(a)

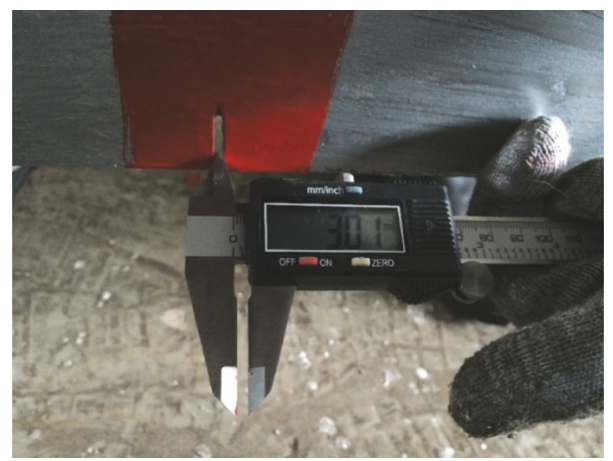

(b)

Figure 6: A general view of the crack. (b) shows the width of the crack (around $0.003 \mathrm{~m}$ ) and (a) shows the height of the crack for delta = $30 \%(0.072 \times 0.3=0.0216 \mathrm{~m} \approx 0.021)$. 


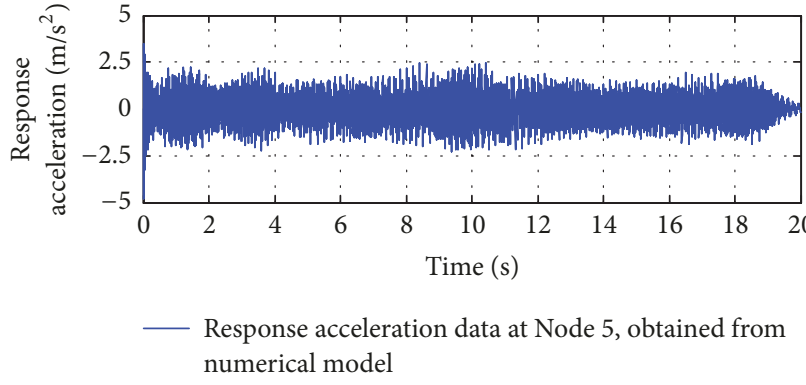

(a) Response acceleration, obtained from numerical model

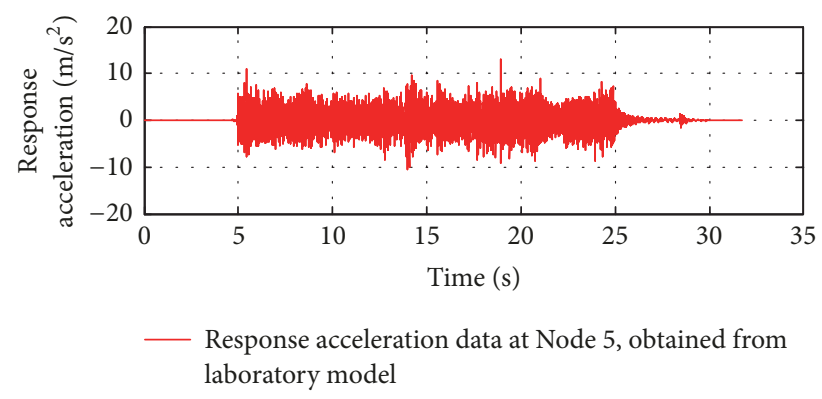

(b) Response acceleration, obtained from laboratory model

Figure 7: Acceleration data at Node 5, as (a) simulated by the numerical model (blue color) and (b) recorded in laboratory (red color).

straight line. Additionally, to check the effect of changes in velocity on the damage detection, three different speeds were considered $(0.3,0.4$, and $0.5 \mathrm{~m} / \mathrm{s})$. The sampling frequency of the acceleration signal was $500 \mathrm{~Hz}$.

3.2. Numerical Modelling and Analysis. According to geometrical dimensions and material properties of the beam model, a corresponding numerical model was established using 3D shell elements. In this numerical model, the beam was divided into 5400 elements, in which linear quadrilateral elements of the type S4R were used for meshing. In the numerical model analysis, four different damage scenarios were considered, as listed in Table 1. Although the numerical model used the same geometrical dimension and material properties, these two models were considered as two separate works. Thus, no comparison is required between numerical and experimental works.

\section{Results and Discussion}

4.1. Preliminary Data. Figure 7 shows the acceleration signal in the mid-span of the beam from the test and numerical model under moving load at $0.3 \mathrm{~m} / \mathrm{s}$. All the 9 sensors recorded the acceleration data simultaneously.

4.2. Detecting Singularities along the Signal. In this paper, the MAF span is set to sampling frequency and MAF is applied to the signal more than once (normally, twice) until the signal is smoothed and free of fluctuations. In a noise-free environment, it is possible to locate the damage using only one accelerometer. Here, based on the established numerical model, the results show that, regardless of the location of the accelerometer along a bridge structure, it can locate the damage accurately. The smoothed signals exhibit an inconsistency in the damage position when a vehicle passes across the structure.

Figure 8 gives smoothed acceleration signals for both damaged and undamaged beams (the damage (delta $=40 \%)$ occurred in the middle of the beam) at different locations obtained from the numerical model using MAF. From Figure 8 , the signals obtained from all nodes can show the damage location easily. In this figure, the horizontal axis is the normalized time, which shows the place of the moving load. For example, at the normalized time of 0.3 on the horizontal axis, the moving load has travelled $30 \%$ of the beam. To get a better result and find the damage position more easily, one can remove the baseline from damaged signals. Figure 9 further gives the smoothed acceleration signals after removing the baseline for Nodes 3,5 , and 7.

4.3. Predicting the Baseline. As shown in Figure 9, all signals can locate the damage following baseline elimination. Given that these signals are the results of applying MAF, it is noticed that MAF removes the vibrations and gives a smoothed signal. So, it is possible to predict the baseline based on applying MAF once more and then removing it from signals to find the damage. This predicted baseline based on MAF is not a real baseline; however, it can serve as a baseline to find the damage. Figure 10 shows the smoothed signal for the damaged beam (delta $=40 \%$ in the middle of the beam) and its predicted baseline. Figure 11 shows damage location in Nodes 2, 3, 5, and 7 based on the predicted baseline according to MAF (the predicted baselines were subtracted from the signals).

As shown in Figure 11, the predicted baselines worked well, and all signals highlighted the singularity around the damage location. The damage showed itself as abnormal vibrations in the smoothed acceleration signal around the damage position. Although Figure 11 shows the abnormal vibrations, it is messy and cannot work if there is a noise or damage that occurred even at a small ratio. Equation (4) defines a damage index to transform the plots to scalar values, as illustrated in Figure 12:

$$
\begin{aligned}
E_{n} & =\sum_{t_{1}}^{t_{2}} A_{\mathrm{arbl}}^{2}, \\
t_{1} & =\frac{L / V}{n_{t}+1} \times \frac{2 n-1}{2}, \\
t_{2} & =\frac{L / V}{n_{t}+1}+t_{1},
\end{aligned}
$$

where $E_{n}$ is the damage index that substitutes a signal by a unique scalar value, $n_{t}$ is the number of the accelerometers, $L$ is the length of the beam, $V$ is the velocity of the vehicle, and $n$ is the number of the nodes. $A_{\mathrm{arbl}}$ is the smoothed acceleration 


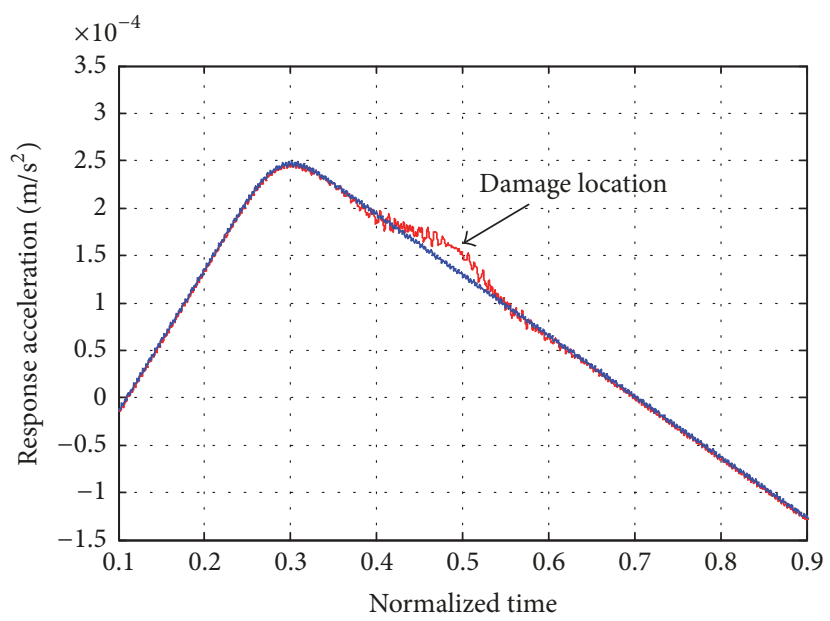

- Smoothed acceleration signal at Node 3 for N5D40, obtained from numerical model

- Smoothed acceleration signal at Node 3 for baseline, obtained from numerical model

(a) Response acceleration at Node 3

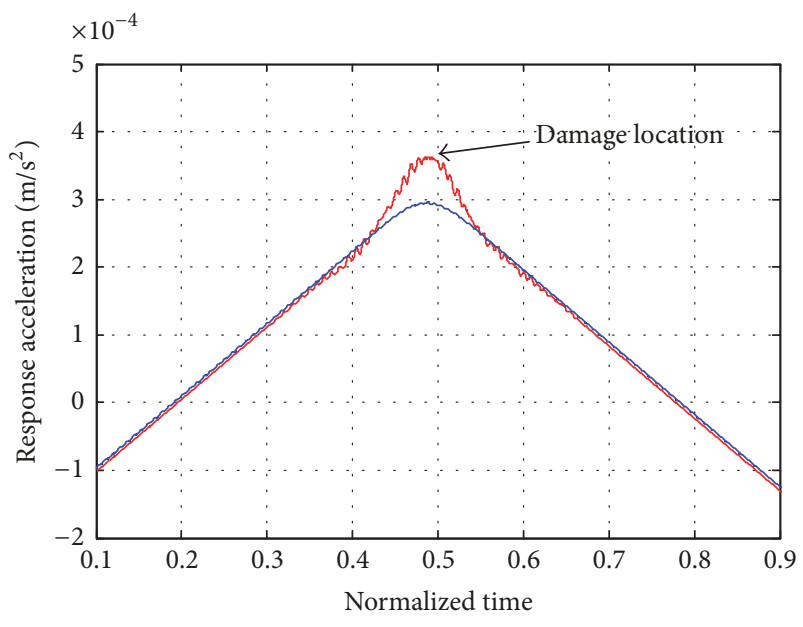

Smoothed acceleration signal at Node 5 for N5D40, obtained from numerical model

- Smoothed acceleration signal at Node 5 for baseline, obtained from numerical model

(b) Response acceleration at Node 5

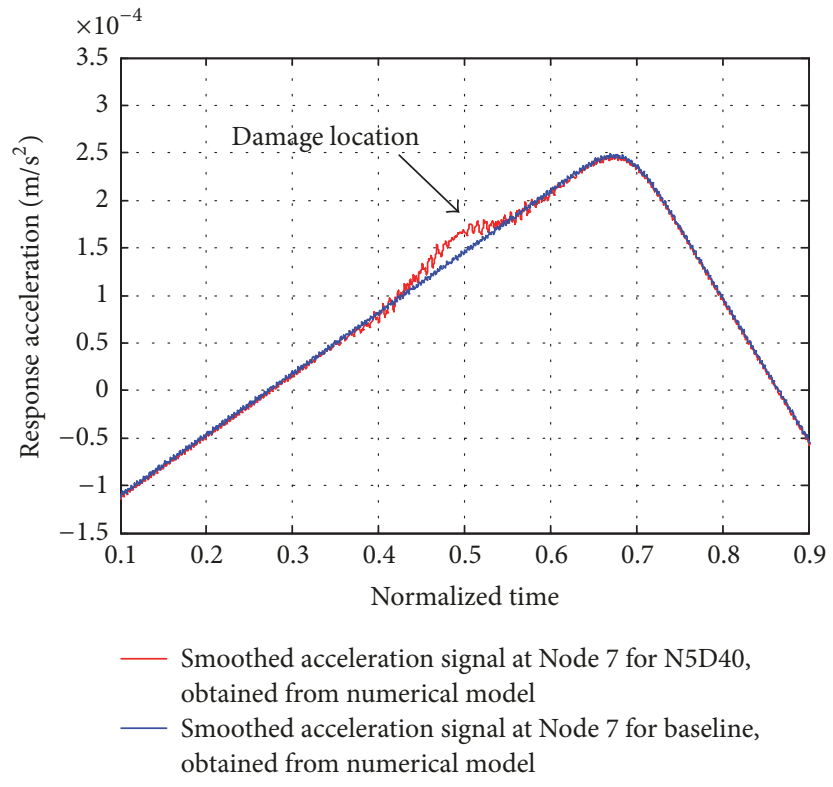

(c) Response acceleration at Node 7

FIGURE 8: The smoothed acceleration signal for both damaged and undamaged beams (the damage occurred in the middle of the beam) at different locations along the beam. Blue color refers to the undamaged beam and orange color denotes the damaged beam: (a) signals from Node 3, (b) signals from Node 5, and (c) signals from Node 7.

TABLE 1: Four damage scenarios considered in the numerical model analysis.

\begin{tabular}{lcccc}
\hline Scenarios & 1 & 2 & 3 & 4 \\
\hline Crack depth-to-beam flange ratio & $40 \%$ & $30 \%$ & $40 \%$ & $30 \%$ \\
Location & At Node 5 (mid-span) & At Node 7 & At Nodes 2 \& 5 & At Nodes 3 \& 7 \\
Name & N5D40 & N7D30 & N2N5D40 & N3N7D30 \\
\hline
\end{tabular}

Note. The scenarios are designated as N (damage location) D (delta). For example, N5D40 refers to a scenario where delta is 40\% at Node 5, or N3N7D30 indicates the one where delta is $30 \%$ at Nodes 3 and 7. 


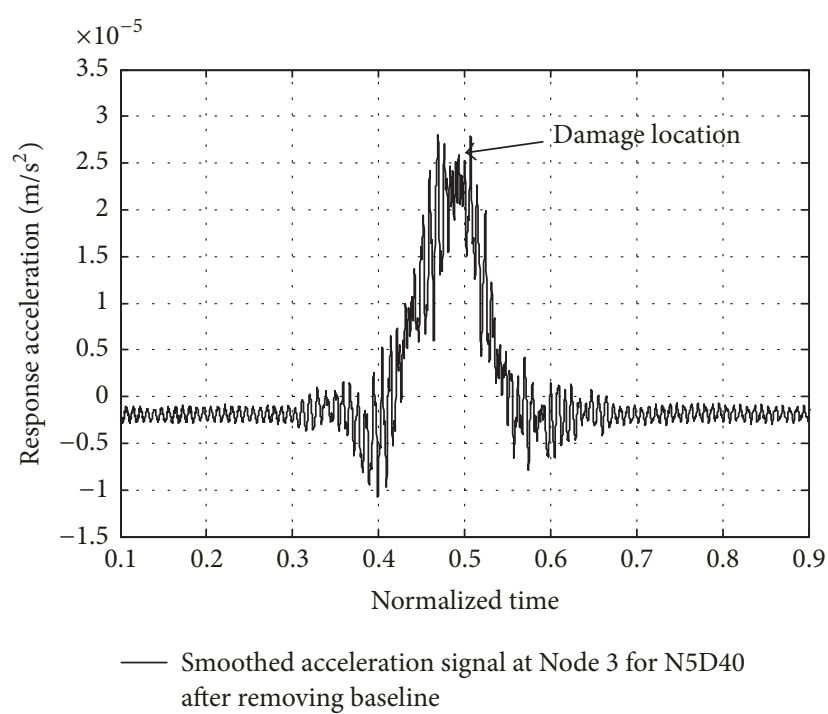

(a) Response acceleration at Node 3

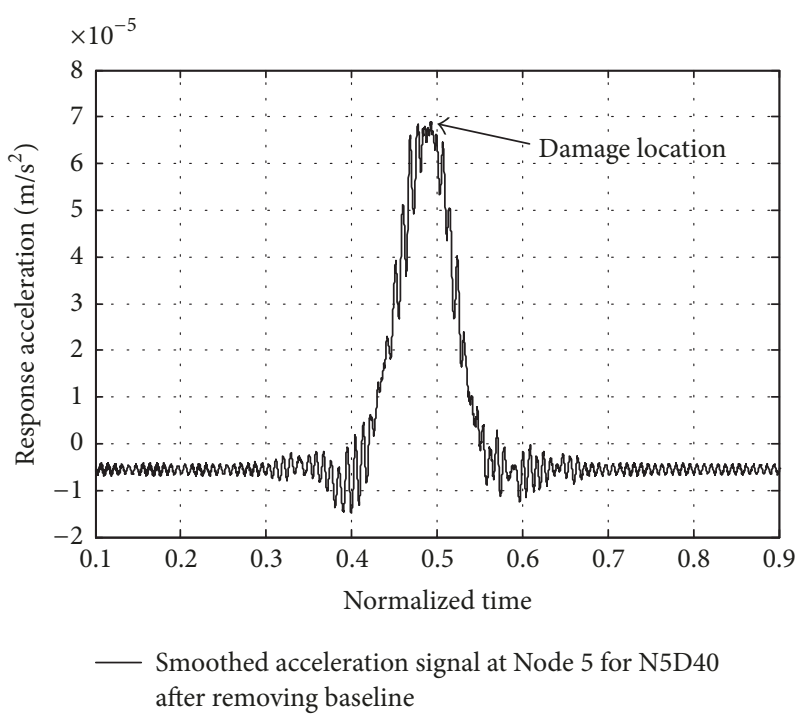

(b) Response acceleration at Node 5

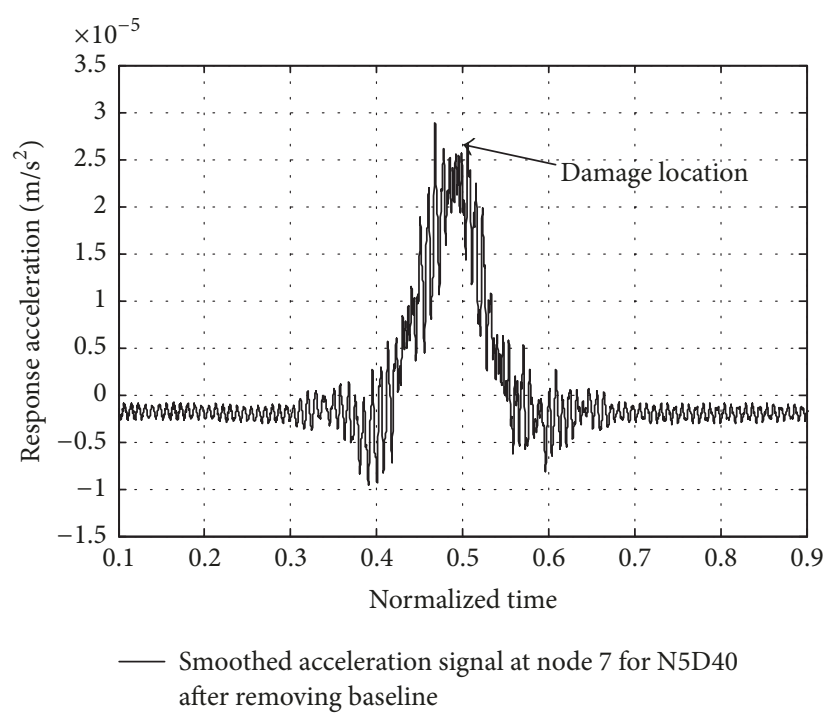

(c) Response acceleration at Node 7

FIGURE 9: The smoothed acceleration signal after removing the baseline (the damage occurred in the middle of the beam) at different locations: (a) signals from Node 3, (b) signals from Node 5, and (c) signals from Node 7.

signal after removing the predicted baseline. For example, if the velocity, the length, $n_{t}$, and $n$ are $0.3 \mathrm{~m} / \mathrm{s}, 6 \mathrm{~m}, 9$, and 4 , respectively, then $t_{1}=7 \mathrm{~s}$ and $t_{2}=9 \mathrm{~s}$. On the other hand, (4) gives sum of the squares of the acceleration data when the moving load is around the accelerometer.

Using (4), one can calculate damage index for all accelerometers. Figure 13 shows the values of damage index for each accelerometer in the damaged beam (N5D40).

Figure 13 shows that the damage index in the mid-span is larger than the other ones. So, it can be seen that the damage exists near the mid-span of the beam. Although the amount of $E$ in this plot is very small (as it is calculated based on finding abnormal vibrations after applying MAF), it still serves both numerical and experimental works satisfactorily with no need for any filtering or any other signal processing operation such as baseline correction. Figure 14 gives the damage index for each sensor along the intact beams N5D40 and N7D30, as obtained from the numerical model.

From Figure 14, it is easy to find the maximum damage index and its related accelerometer (node). As seen, Figure 14(a) follows a regular pattern without any significant difference between the data points. Additionally, the values depicted in this figure are smaller than the ones on the damaged beam. Thus, no damage is assumed to happen in this case.

As mentioned above and shown in Figures 5 and 6, an experimental work was made and the acceleration data was recorded under a moving vehicle load. Figure 15 shows the damage indexes for each accelerometer using the proposed method. 


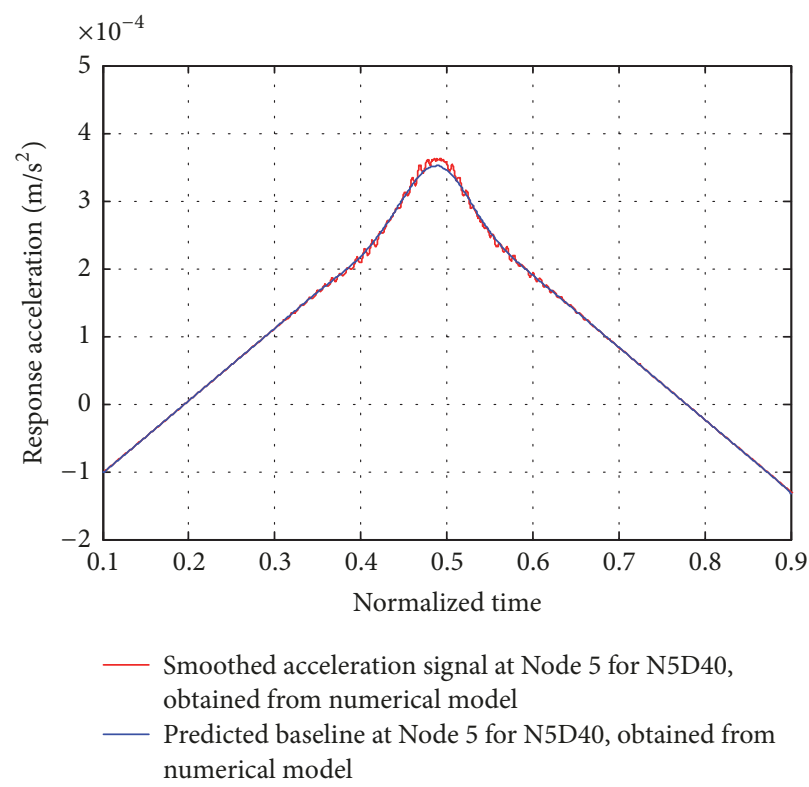

Figure 10: The smoothed acceleration signal obtained at Node 5 with delta $=40 \%$ (red color) and its predicted baseline based on MAF (blue color).

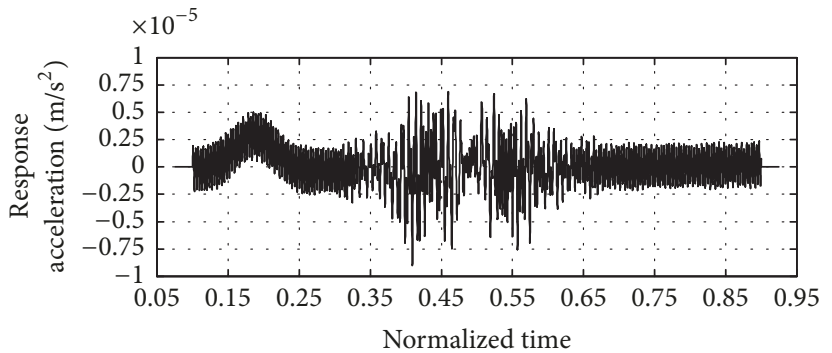

- Smoothed acceleration signal at Node 2 for N5D40 after removing the predicted baseline

(a) Smoothed acceleration signal at Node 2

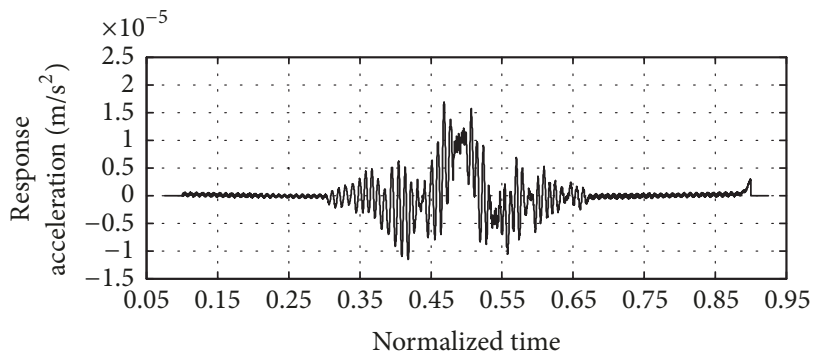

- Smoothed acceleration signal at Node 5 for N5D40 after removing the predicted baseline

(c) Smoothed acceleration signal at Node 5

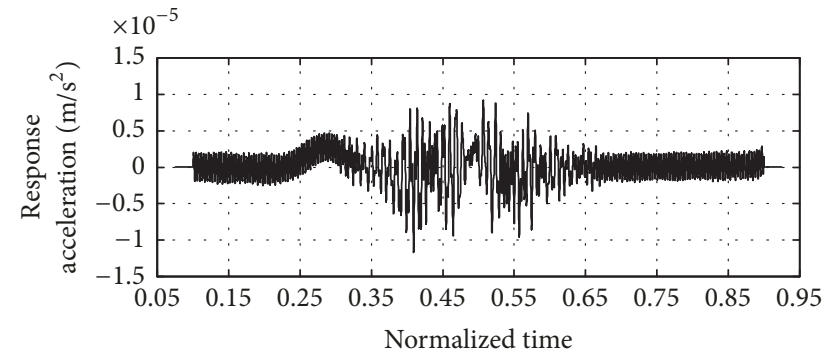

- Smoothed acceleration signal at Node 3 for N5D40 after removing the predicted baseline

(b) Smoothed acceleration signal at Node 3

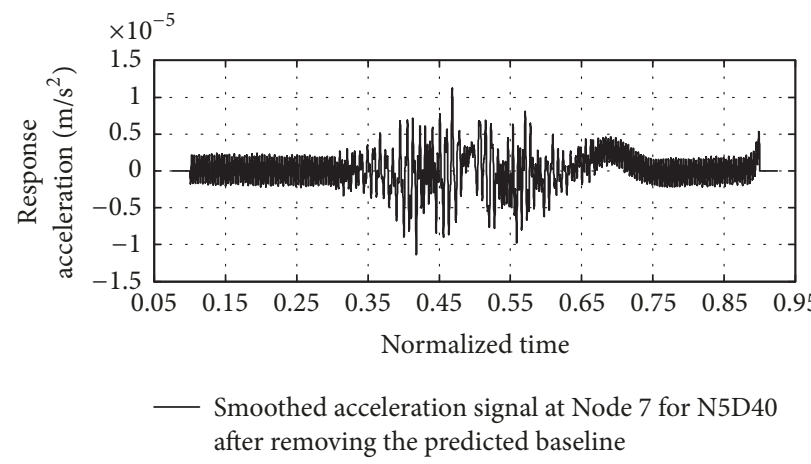

(d) Smoothed acceleration signal at Node 7

FIGURE 11: The smoothed acceleration signals after removing the predicted baseline (the damage occurred in the middle of the beam) at different locations: (a) signal from Node 2, (b) signal from Node 3, (c) signal from Node 5, and (d) signal from Node 7.

Figure 15 proves that the proposed method does not need a baseline correction for detecting damage location along noisy signals. The experimental work had associated noise due to the changes in the baseline of the accelerometers and also due to the environmental noise. Because of this noise, extra vibrations are observed with the behavior of the predicted baseline changed slightly. MAF attenuates the noise and makes the signal smooth, so that, in the absence of noise 


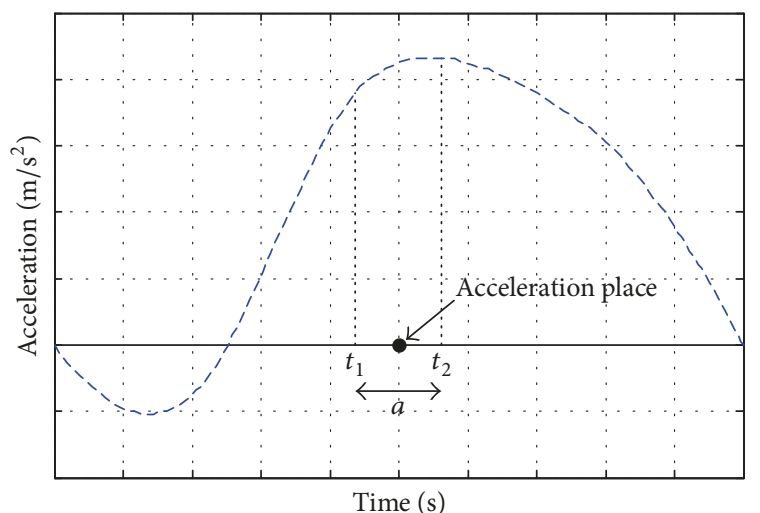

FIGURE 12: Schematic of calculating a representative scalar value for an accelerometer. $a=$ the domain of data from $t_{1}$ to $t_{2}$.

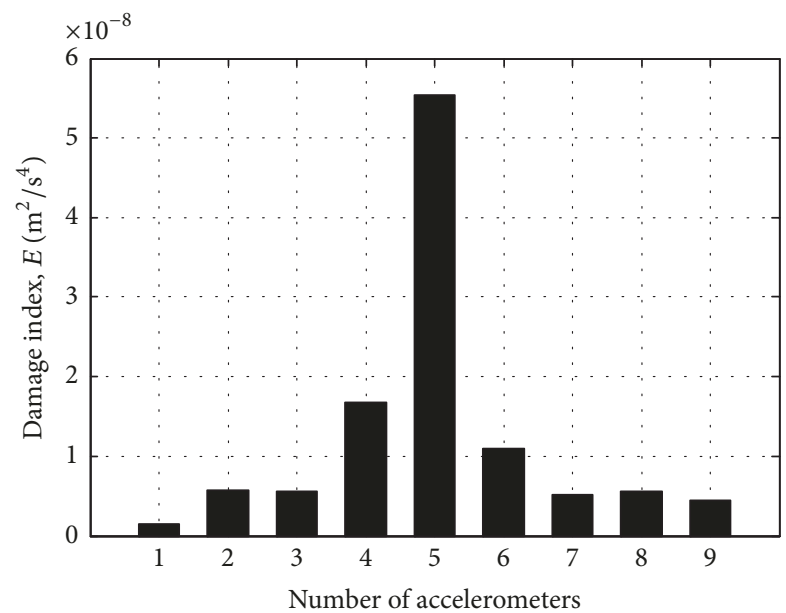

Case N5D40

FIGURE 13: Scalar values for each accelerometer in the damaged beam $(\mathrm{N} 5 \mathrm{D} 40)$ (velocity $=0.3 \mathrm{~m} / \mathrm{s})$.

after applying MAF, the signal is smoother and the damage index is very small. So, the presence of noise results in much smaller $E_{n}$ values in the numerical model rather than the experimental model, while both models show principally the same behavior and pattern.

4.4. Effect of Velocity of Moving Load. Effects of changes in the velocity of the moving load were studied. Accordingly, it was observed that, with increasing the speed of the moving load, the accuracy of the proposed method will be decreased $[2,5,21]$. Here in this work, the accuracy was studied at three different velocities $(0.3,0.4$, and $0.5 \mathrm{~m} / \mathrm{s})$, with the results proving the above-mentioned statement (damage detection failed at velocities equal to or greater than $0.5 \mathrm{~m} / \mathrm{s}$ ). Furthermore, at velocities slower than $0.3 \mathrm{~m} / \mathrm{s}$ or faster than $0.4 \mathrm{~m} / \mathrm{s}$, either MAF span should be changed or the MAF should be applied more times to get a better accuracy. Here in this work, for the MAF span of 500, the velocity range $0.3-0.4 \mathrm{~m} / \mathrm{s}$ gave perfect results.

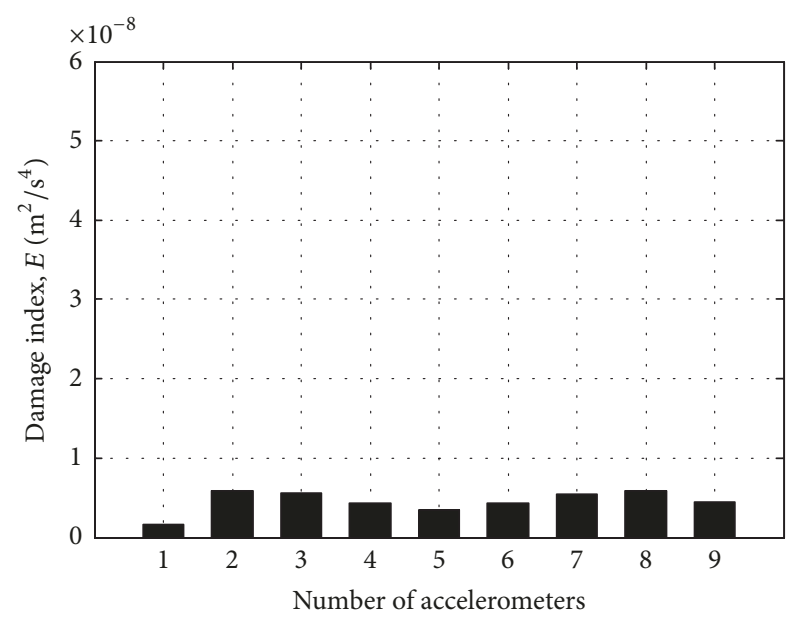

Case with no damage

(a) Case no-damage from numerical model

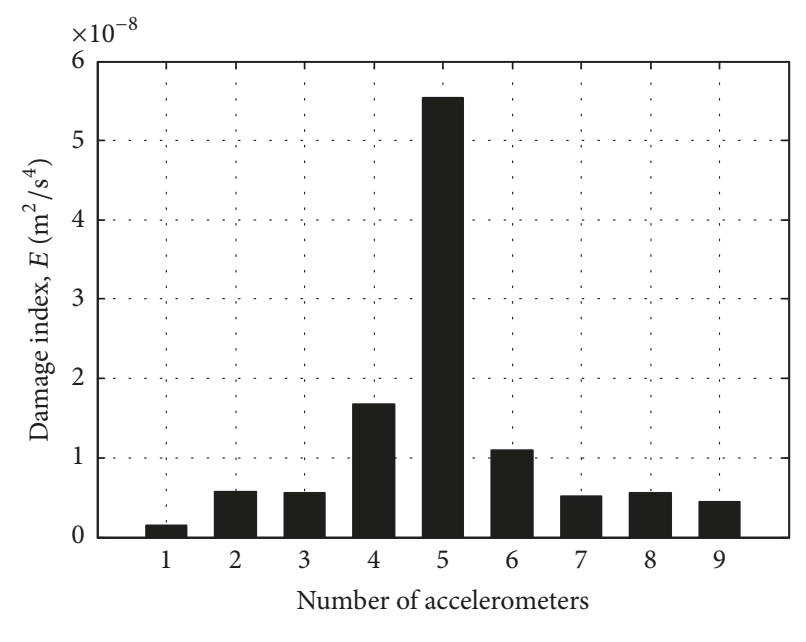

- Case N5D40

(b) Case N5D40 from numerical model

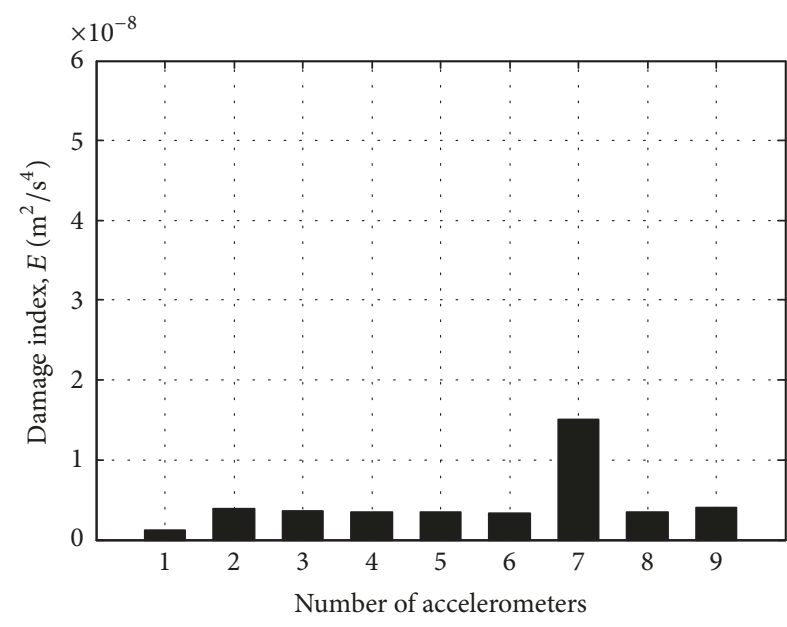

Case N7D30

(c) Case N7D30 from numerical model

FIGURE 14: Distribution of damage index along the beams for different accelerometers (velocity $=0.3 \mathrm{~m} / \mathrm{s}$ ): (a) without any damage, $(\mathrm{b})$ delta $=40$ at Node 5 , and (c) delta $=30$ at Node 7 . 


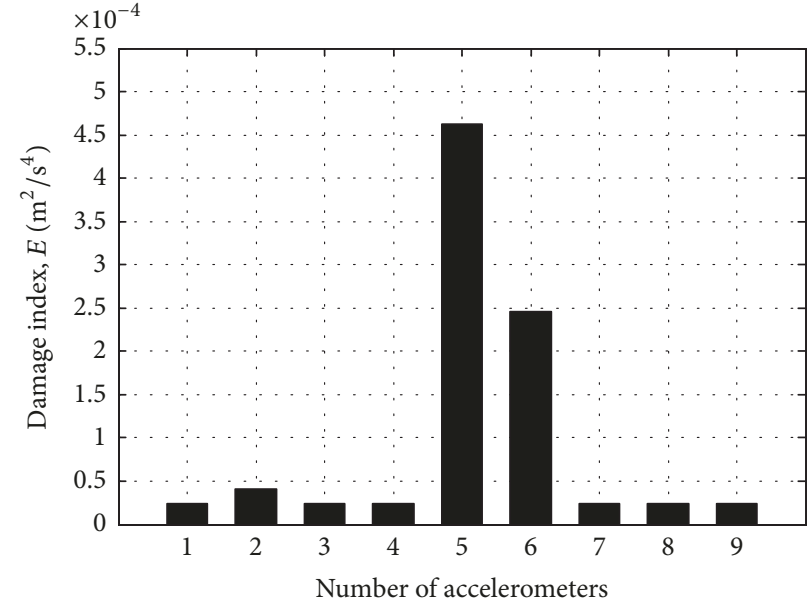

Case N5D40, obtained from laboratory

(a) Case N5D40 from laboratory model

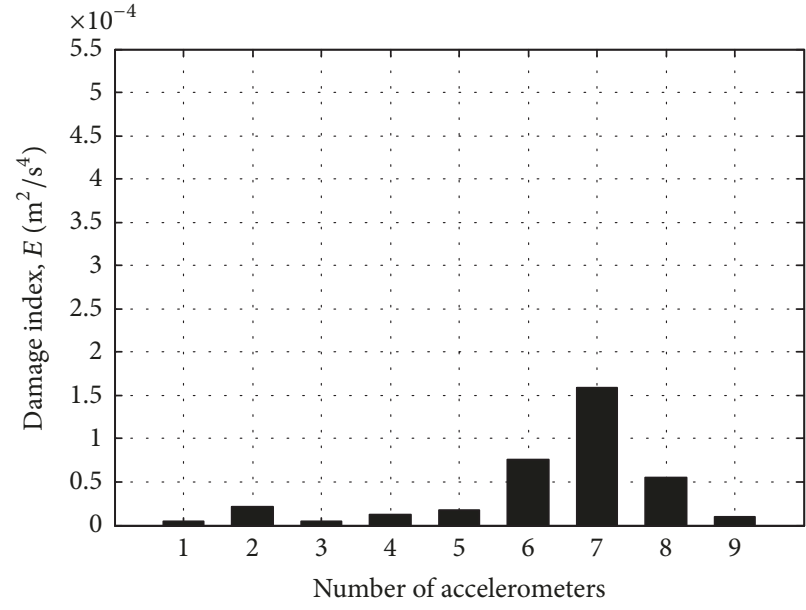

Case N7D30, obtained from laboratory

(b) Case N7D30 from laboratory model

Figure 15: Distribution of the damage index along the beams, as obtained from laboratory tests: (a) delta $=40$ at Node 5 (velocity $=0.3 \mathrm{~m} / \mathrm{s}$ ) and (b) delta $=30$ at Node 7 (velocity $=0.3 \mathrm{~m} / \mathrm{s}$ ).

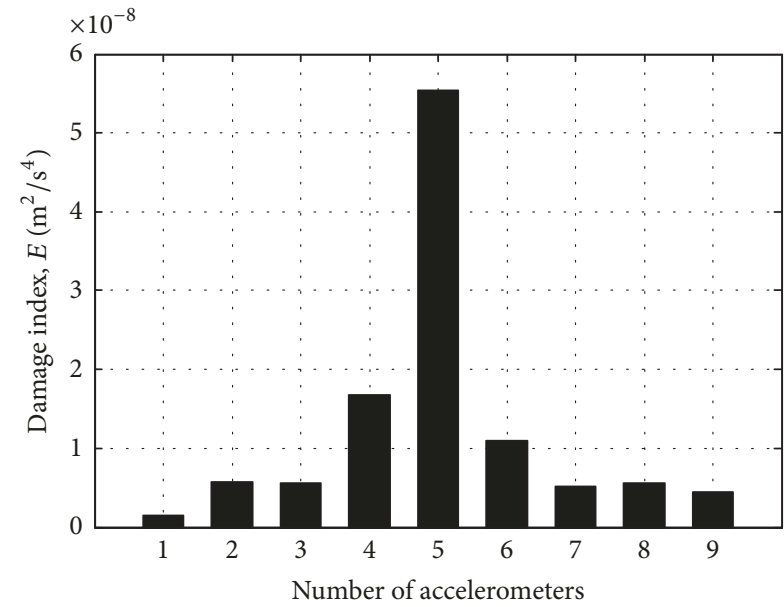

Case N5D40, speed $0.3 \mathrm{~m} / \mathrm{s}$

(a) N5D40, speed $0.3(\mathrm{~m} / \mathrm{s})$

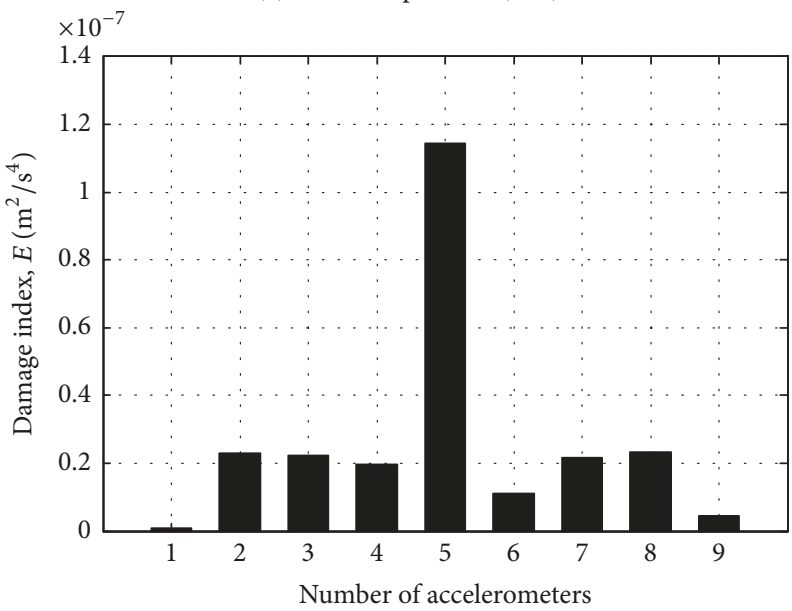

Case N5D40, speed $0.4 \mathrm{~m} / \mathrm{s}$

(c) N5D40, speed $0.4(\mathrm{~m} / \mathrm{s})$

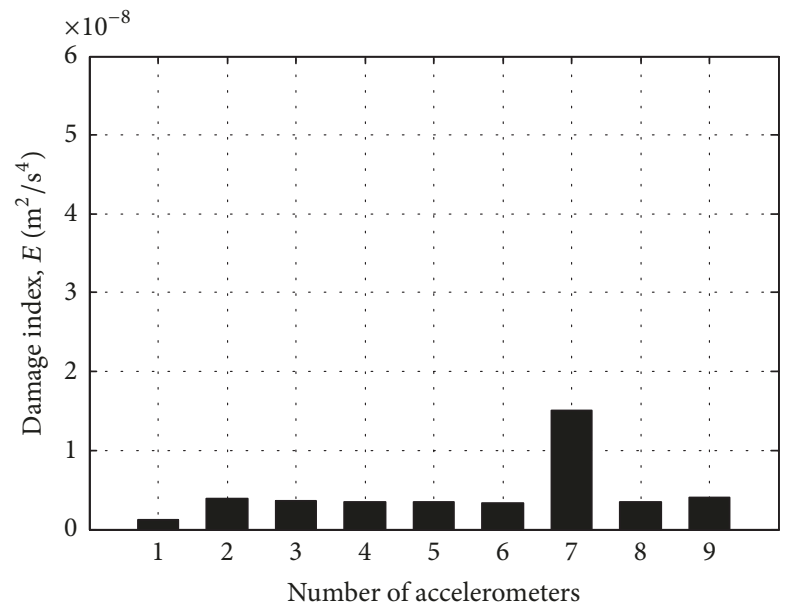

Case N7D30, speed $0.3 \mathrm{~m} / \mathrm{s}$

(b) N7D30, speed $0.3(\mathrm{~m} / \mathrm{s})$

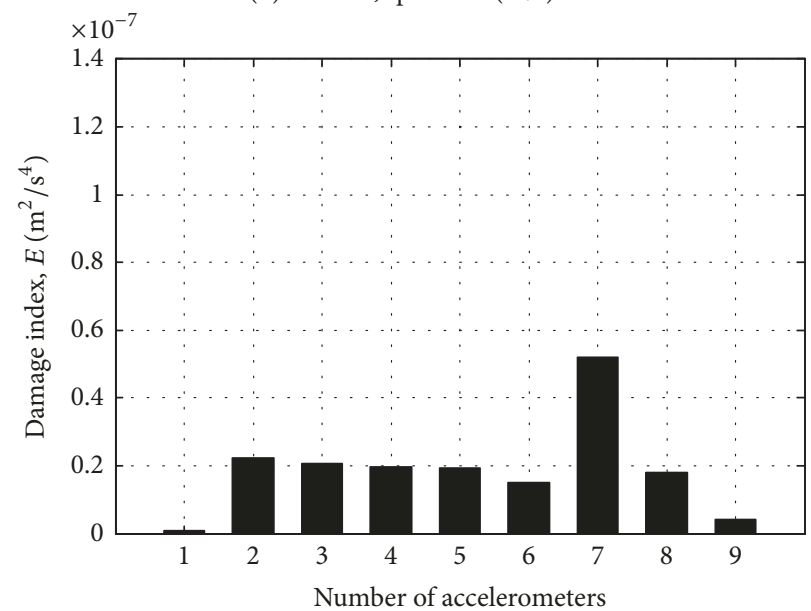

Case N7D30, speed $0.4 \mathrm{~m} / \mathrm{s}$

(d) N7D30, speed $0.4(\mathrm{~m} / \mathrm{s})$

FIGURE 16: Scalar values of damage index $E_{n}$ for all accelerometers at different locations and load moving velocities, as obtained from the numerical model: (a) case N5D40 (velocity $=0.3 \mathrm{~m} / \mathrm{s}$ ), (b) case N7D30 (velocity $=0.3 \mathrm{~m} / \mathrm{s}$ ), (c) case N5D40 (velocity $=0.4 \mathrm{~m} / \mathrm{s}$ ), and (d) case N7D30 (velocity $=0.4 \mathrm{~m} / \mathrm{s}$ ). 


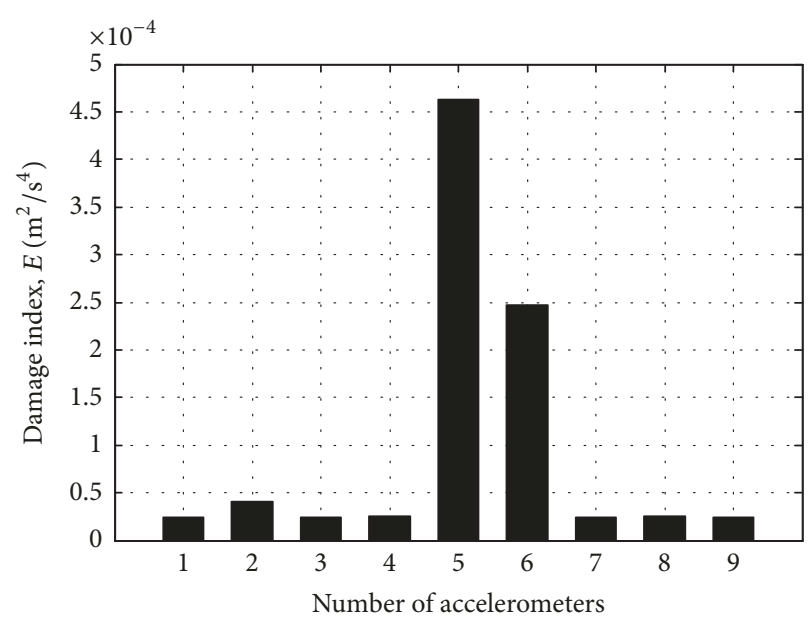

Case N5D40, speed $0.3 \mathrm{~m} / \mathrm{s}$

(a) N5D40, speed $0.3(\mathrm{~m} / \mathrm{s})$

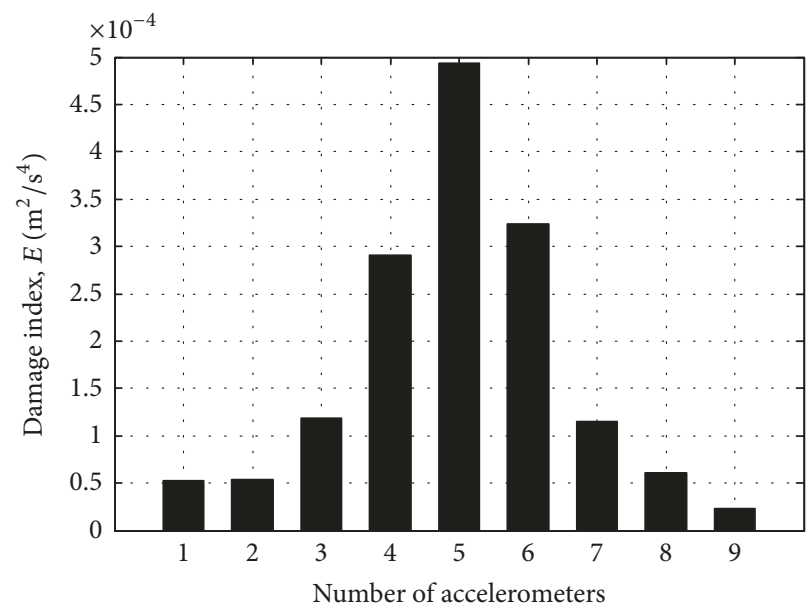

Case N5D40, speed $0.4 \mathrm{~m} / \mathrm{s}$

(c) N5D40, speed $0.4(\mathrm{~m} / \mathrm{s})$

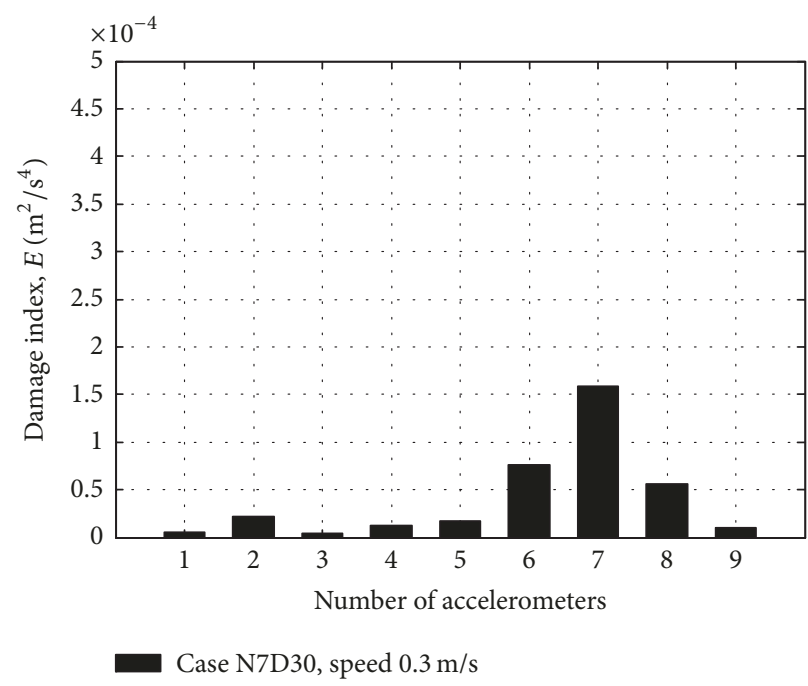

(b) N7D30, speed $0.3(\mathrm{~m} / \mathrm{s})$

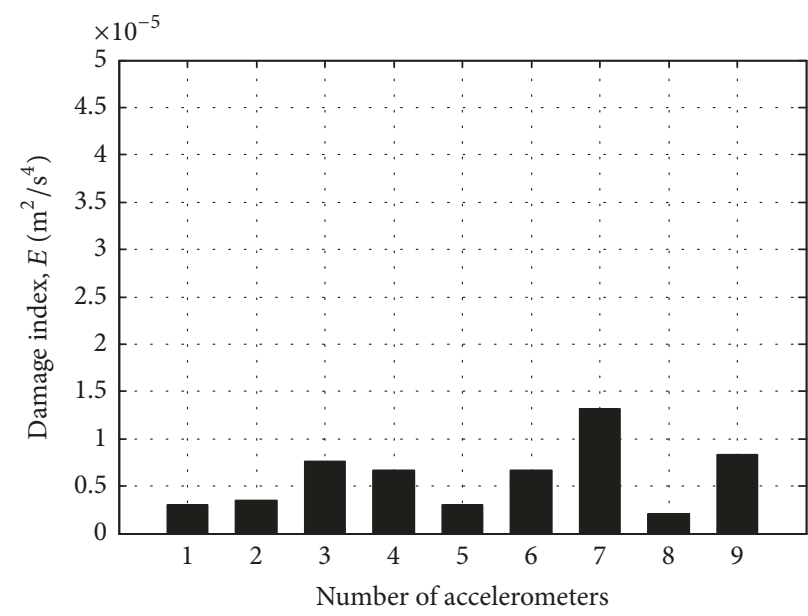

Case N7D30, speed $0.4 \mathrm{~m} / \mathrm{s}$

(d) N7D30, speed $0.4(\mathrm{~m} / \mathrm{s})$

FiguRE 17: Scalar values of the damage index $E_{n}$ for all accelerometers at different locations and load moving velocities, as obtained from laboratory test data: (a) case N5D40 (velocity $=0.3 \mathrm{~m} / \mathrm{s}$ ), (b) case N7D30 (velocity $=0.3 \mathrm{~m} / \mathrm{s}$ ), (c) case N5D40 (velocity $=0.4 \mathrm{~m} / \mathrm{s}$ ), and $(\mathrm{d}$ ) case N7D30 (velocity $=0.4 \mathrm{~m} / \mathrm{s}$ ).

Figures 16 and 17 show the effect of two different velocities on $E_{n}$, as obtained from the numerical model and laboratory data.

In Figure 16(b), the damage index close to thirty-percent damage location was calculated to be $400 \%$ larger than other values for $v=0.3 \mathrm{~m} / \mathrm{s}$ in noise-free numerical model. This difference was then decreased to $200 \%$ for $v=0.4 \mathrm{~m} / \mathrm{s}$ (Figure 16(d)). Thus, by increasing the speed, the difference between the values obtained around the damage location and other places along the beam is decreased. In addition, this difference decreases more in noisy environment as shown in Figure 17. In Figures 17(b) and 17(d), the maximum difference is less than $100 \%$ due to noises incorporated in the model. The difference then decreases more by increasing the speed.
4.5. Multiple Damage Scenarios. So far, the procedure to find singularity and estimate damage location along the beam was described and the damage was successfully detected in the laboratory and numerical models. However, all explanations given so far referred to the case where only one damage scenario exists along the model. In this section, in order to investigate the case where multiple damage scenarios are present in the beam, two further scenarios were defined in the numerical model. In the first scenario, delta $=0.4$ at Nodes 2 and $5(\mathrm{~N} 2 \mathrm{~N} 5 \mathrm{D} 40)$, while the second scenario had delta $=0.3$ at Nodes 3 and 7 (N3N7D30).

Figure 18 shows the damage indexes obtained from the proposed method when there are two damage scenarios along the beam. The figure indicates how MAF can find the multiple 


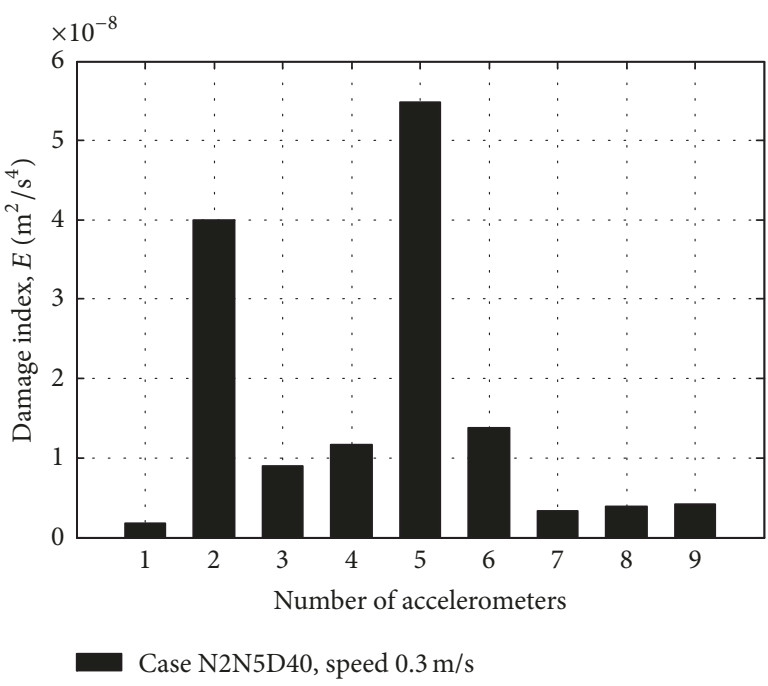

(a) N2N5D40

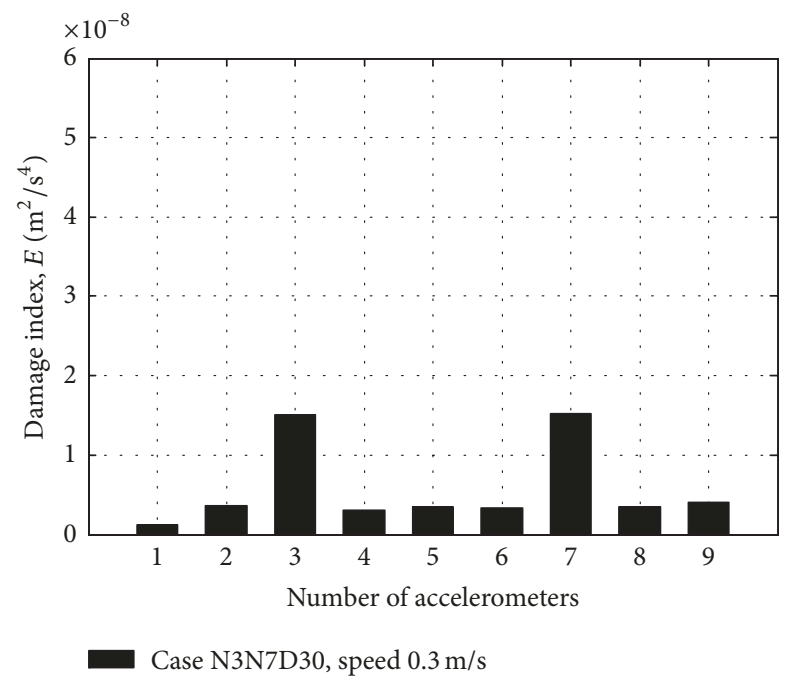

(b) N3N7D30

FIGURE 18: Scalar values of the damage index $E_{n}$ for all accelerometers for the multiple damage scenarios: (a) case N2N5D40 (velocity = $0.3 \mathrm{~m} / \mathrm{s}$ ) and (b) case N3N7D30 (velocity $=0.3 \mathrm{~m} / \mathrm{s}$ ).

damage scenarios in the beam under a moving load travelling at $0.3 \mathrm{~m} / \mathrm{s}$.

Using the proposed model in a noisy environment is accompanied by a margin of error. However, it can accurately detect the multiple damage scenario in noise-free data with speed equal to or less than $0.3 \mathrm{~m} / \mathrm{s}$. Having noises incorporated in data and also increasing the truck speed make some local maximums, which cannot be considered as damage location. Thus, to detect the multidamage locations using the proposed method, these two conditions must be considered: (1) the noise ratio should be small and (2) the velocity should be highly adjusted.

\section{Conclusion}

This paper proposed an output-only method where MAF was used to make the acceleration signal smooth, thereby highlighting abnormal vibrations around the damage location without applying any signal processing or correction technique (such as the baseline correction). Since the proposed method could predict the baseline, there was no need for calculating the response of an intact structure. Therefore, the proposed method is a baseline-free method which only requires acceleration signal data to identify damage. follows:

The main conclusions drawn from this study are as

(1) It is proved that the damage location can be found using only one accelerometer along a steel beam in a noise-free environment. The location of this accelerometer is also irrelevant and it can be installed anywhere along the steel beam except near the supports.

(2) Performance of the proposed method can be improved by defining a damage index, En, that assigned a scalar value to each signal to estimate damage location along a simply supported steel beam.

(3) Investigating the effect of load moving velocity, it was shown that, by increasing the velocity, the proposed method had its accuracy decreased significantly.

(4) Accuracy of the proposed method was examined through two models, namely, a numerical and an experimental model.

(5) It was indicated that the proposed method can easily find the location of a single damage on a noisy signal; it also succeeded to find multiple damage scenarios on noise-free signals obtained from the examined numerical model.

Last but not least, the proposed method does not need modal identification for damage detection; this can effectively reduce the time and cost of SHM through this method, as compared to other approaches to SHM. Thus, this method provides a very useful tool for damage detection in complicated structures. This topic will be further studied by the authors in their future research on a cable-arch bridge model in a laboratory.

\section{Conflicts of Interest}

The authors declare that they have no conflicts of interest.

\section{Acknowledgments}

This work is financially supported by the Zhejiang University scholarships for foreign students, Cyrus Tang Foundation of China and Natural Science Foundation of China (NSFC, no. 51178416), and the College of Architectural and Civil Engineering of Zhejiang University as well. 


\section{References}

[1] S. R. Ibrahim, "Random decrement technique for modal identification of structures," Journal of Spacecraft and Rockets, vol. 14, no. 11, pp. 696-700, 1977.

[2] D. Hester and A. González, "A wavelet-based damage detection algorithm based on bridge acceleration response to a vehicle," Mechanical Systems and Signal Processing, vol. 28, pp. 145-166, 2012.

[3] K. Balafas and A. S. Kiremidjian, "Development and validation of a novel earthquake damage estimation scheme based on the continuous wavelet transform of input and output acceleration measurements," Earthquake Engineering \& Structural Dynamics, vol. 44, no. 4, pp. 501-522, 2015.

[4] D. Cantero and B. Basu, "Railway infrastructure damage detection using wavelet transformed acceleration response of traversing vehicle," Structural Control and Health Monitoring, vol. 22, no. 1, pp. 62-70, 2015.

[5] D. Hester and A. González, "Impact of road profile when detecting a localised damage from bridge acceleration response to a moving vehicle," Key Engineering Materials, vol. 569-570, pp. 199-206, 2013.

[6] J. K. Vandiver, A. B. Dunwoody, R. B. Campbell, and M. F. Cook, "A mathematical basis forthe random decrement vibration signature analysis technique," Journal of Mechanical Design, vol. 104, no. 2, pp. 307-313, 1982.

[7] J. W. Lee, J. D. Kim, C. B. Yun, J. H. Yi, and J. M. Shim, "Healthmonitoring method for bridges under ordinary traffic loadings," Journal of Sound and Vibration, vol. 257, no. 2, pp. 247-264, 2002.

[8] X. H. He, X. G. Hua, Z. Q. Chen, and F. L. Huang, "EMD-based random decrement technique for modal parameter identification of an existing railway bridge," Engineering Structures, vol. 33, no. 4, pp. 1348-1356, 2011.

[9] H. Buff, A. Friedmann, M. Koch, T. Bartel, and M. Kauba, "Design of a random decrement method based structural health monitoring system," Shock and Vibration, vol. 19, no. 5, pp. 787794, 2012.

[10] F. Poncelet, G. Kerschen, J.-C. Golinval, and D. Verhelst, "Output-only modal analysis using blind source separation techniques," Mechanical Systems and Signal Processing, vol. 21, no. 6, pp. 2335-2358, 2007.

[11] G. Kerschen, F. Poncelet, and J.-C. Golinval, "Physical interpretation of independent component analysis in structural dynamics," Mechanical Systems and Signal Processing, vol. 21, no. 4, pp. 1561-1575, 2007.

[12] W. Zhou and D. Chelidze, "Blind source separation based vibration mode identification," Mechanical Systems and Signal Processing, vol. 21, no. 8, pp. 3072-3087, 2007.

[13] C. Huang and S. Nagarajaiah, "Experimental study on bridge structural health monitoring using blind source separation method: Arch bridge," Structural Monitoring and Maintenance, vol. 1, no. 1, pp. 69-87, 2014.

[14] C. H. Loh, T. Y. Hung, S. F. Chen, and W. T. Hsu, "Damage detection in bridge structure using vibration data under random travelling vehicle loads," Journal of Physics: Conference Series, vol. 628, no. 1, Article ID 012044, 2015.

[15] H. Cole Jr, "On-the-line analysis of random vibrations," in Proceedings of the 9th Structural Dynamics and Materials Conference, 1968.
[16] A.-M. Yan and J.-C. Golinval, "Null subspace-based damage detection of structures using vibration measurements," Mechanical Systems and Signal Processing, vol. 20, no. 3, pp. 611-626, 2006.

[17] A.-M. Yan, P. De Boe, and J.-C. Golinval, "Structural damage diagnosis by Kalman model based on stochastic subspace identification," Structural Health Monitoring, vol. 3, no. 2, pp. 103-119, 2004

[18] A. M. Yan, P. D. Boe, and J. C. Golinval, "Structural integral monitoring by vibration measurements," FM2003 - Structural Integrity and Materials Aging, vol. 4, no. 2, pp. 363-370, 2003.

[19] R. Rajagopalan, "Generalized causal moving average (GCMA) smoothing filter for real-time applications," in Proceedings of the Optical Science and Technology, SPIE's 48th Annual Meeting, pp. 426-433, International Society for Optics and Photonics, USA, August 2003

[20] S. W. Smith, The Scientist and Engineer's Guide to Digital Signal Processing, Elsevier, 1997.

[21] A. González and D. Hester, "An investigation into the acceleration response of a damaged beam-type structure to a moving force," Journal of Sound and Vibration, vol. 332, no. 13, pp. 32013217, 2013. 


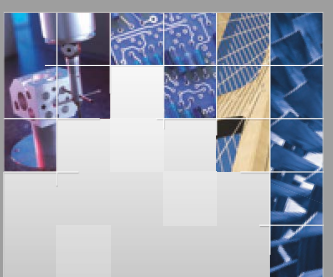

\section{Enfincering}
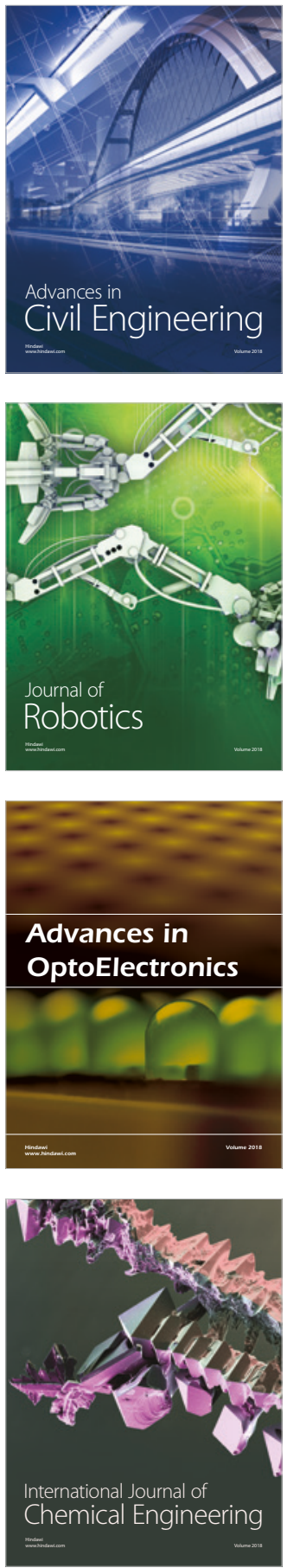

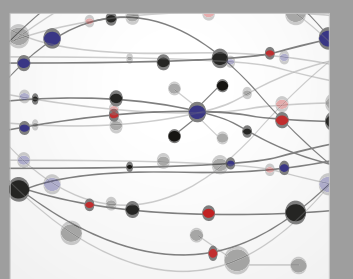

\section{Rotating \\ Machinery}

The Scientific World Journal

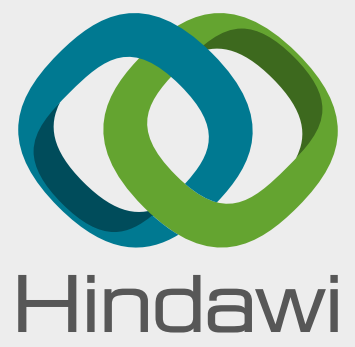

Submit your manuscripts at

www.hindawi.com
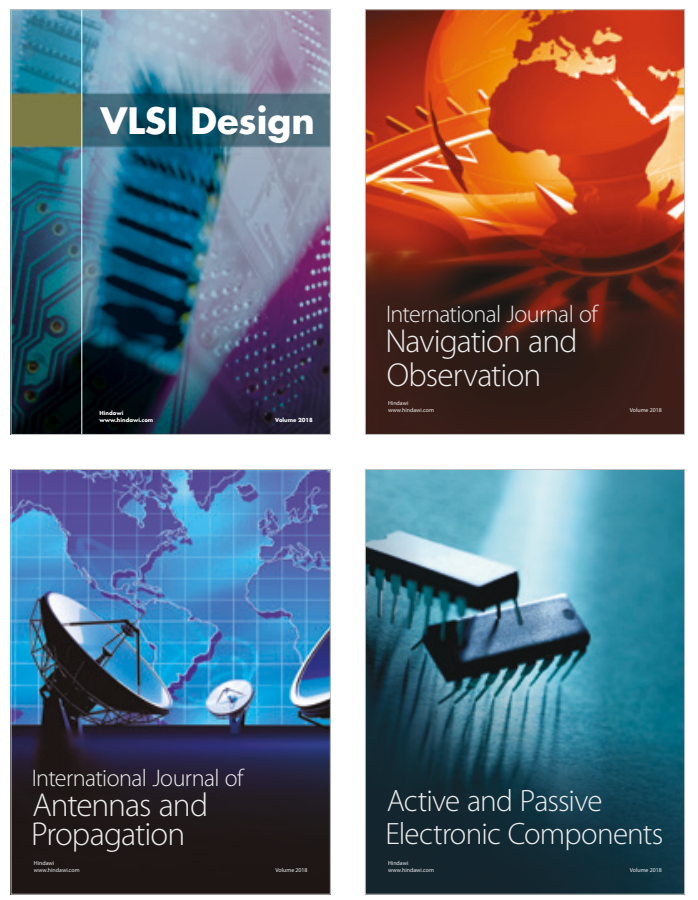
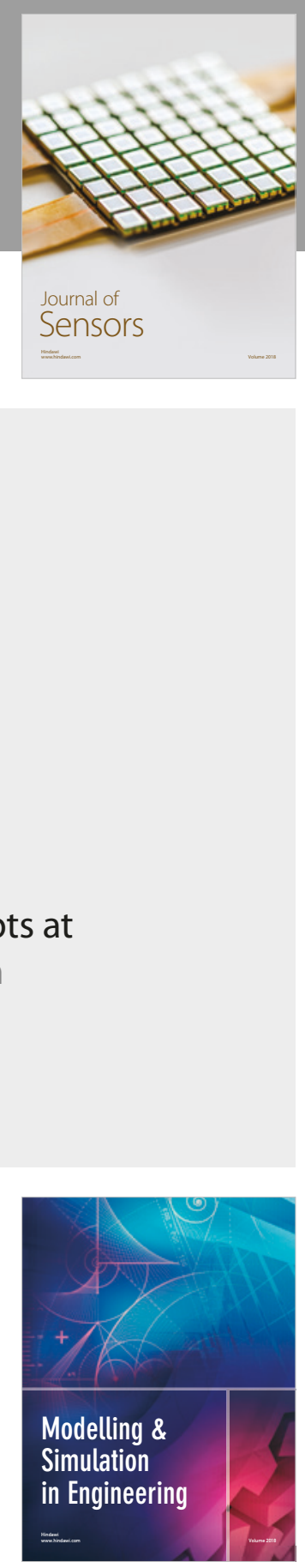

\section{Advances \\ Multimedia}
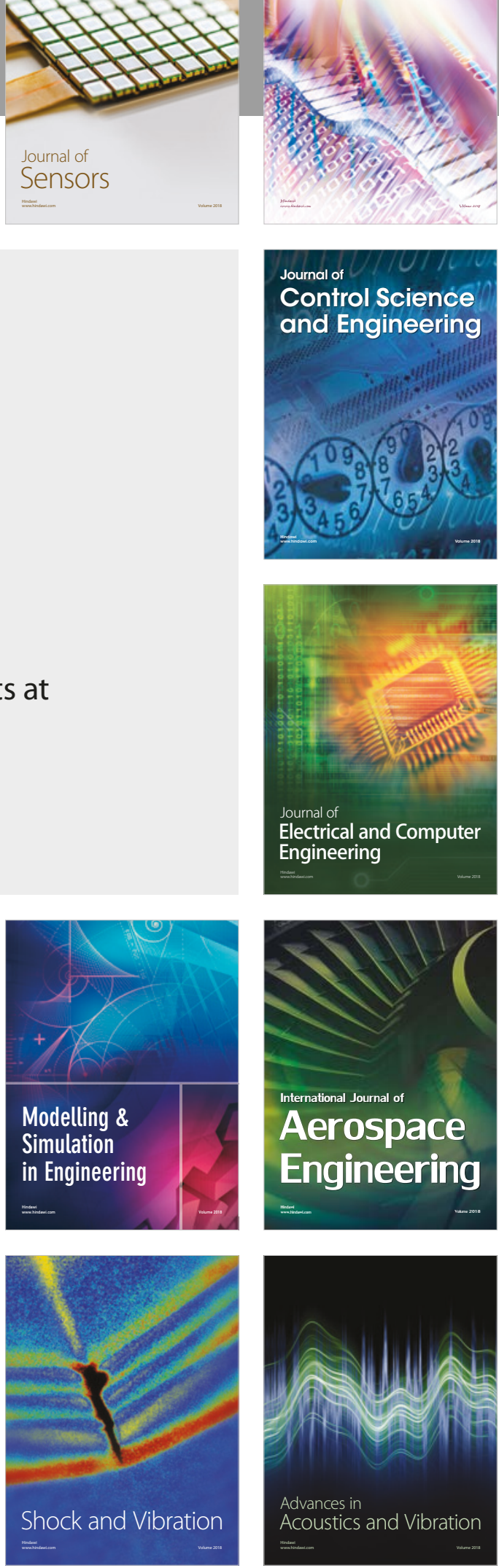